\title{
Efeitos das alterações no preço e na produtividade da produção de leite no Rio Grande do Sul
}

\author{
Julcemar Bruno Zilli* \\ Júnior Candaten \\ Lidiani Nunes*****
}

\section{Resumo}

Este artigo tem o objetivo de analisar os impactos da quantidade de animais, da produtividade e do preço na geração do valor de produção do leite, incidente sobre a taxa de crescimento anual do valor da produção estadual nos maiores municípios produtores do estado do Rio Grande do Sul. Para tanto, utilizou-se o método estrutural-diferencial, o modelo shift-share, com dados de produção, produtividade, valor da produção (Fundação de Economia e Estatística Siegfried Emanuel Heuser) e preço do leite (Centro de Estudos Avançados em Economia Aplicada da Escola Superior de Agricultura Luiz de Queiroz). Desse modo, constatou-se que o efeito preço é um grande responsável pelo aumento da taxa de crescimento, proporcionado pela contínua elevação da commodity. Entretanto, o efeito produtividade exerce papel importante na oferta de leite no mercado examinado, que apresenta efeito superior e significativo ao verificado no rebanho. Assim, concluiu-se que o aumento na produção leiteira ocorreu devido ao aumento do rebanho e, de forma mais intensa, aos ganhos de produtividade que foram percebidos no período analisado.

Palavras-chave: Leite. Shift-share. Rebanho. Produtividade. Preço.

* Doutor em Economia Aplicada pela Escola Superior de Agricultura Luiz de Queiroz - Universidade de São Paulo. Professor da Universidade de Passo Fundo. E-mail: jbzilli@upf.br

** Pós-graduando em Economia e Gestão Empresarial pela Universidade de Passo Fundo. E-mail: juniorcandaten@hotmail.com

**** Pós-graduando em Economia e Gestão Empresarial pela Universidade de Passo Fundo. E-mail: lidiani1000@hotmail.com

http://dx.doi.org/10.5335/rtee.v21i45.6190

Submissão: 25/11/2014. Aceite: 20/06/2015. 


\section{Introdução}

O fim do tabelamento dos preços na década de 1990 marcou o fim da intervenção do Estado nos preços do leite, o que, associado à abertura comercial, gerou maior ingresso de empresas no ramo leiteiro, resultado das vantagens e facilidades disponíveis no Brasil.

Segundo Ferreira Júnior e Teixeira (2005), essas mudanças ocasionaram pressões competitivas no setor, após a entrada de novas e fortes empresas, assim como o aumento das importações de lácteos. Além disso, os autores afirmam que essas mudanças forçaram as empresas nacionais a se especializar para competir com as multinacionais que estavam se instalando no Brasil. As empresas de laticínios tornaram-se grandes, concentradoras, e com capacidade para atender a todo o mercado interno e a produção excedente destinada à exportação (MARION FILHO; FAGUNDES; SCHUMACHER, 2011).

Essas transformações ocorridas no setor lácteo são vistas positivamente por Finamore e Montoya (2005) ao afirmarem que as novas políticas desse cenário divergente possibilitaram ganhos de produtividade. Os autores relatam que a integração indústria e produtor, antes imperceptível, coordenando e auxiliando o setor primário, desempenhou melhoramentos produtivos, qualitativos e maiores retornos econômicos à cadeia produtora.

Essas interações entre os segmentos da cadeia produtiva do leite podem ser observadas pela elevação de $78 \%$ na produção nacional de lácteos, passando de 880,5 milhões de litros, em 1997, para 1,5 bilhão de litros, em 2012, de acordo com dados do Instituto Brasileiro de Geografia e Estatística (IBGE) (2012a).

O aumento da produção nacional ocorreu com a grande participação das Regiões Sudeste e Sul, concomitantemente, pois é nesses locais que se encontram os maiores produtores nacionais de leite e derivados assim como as indústrias processadoras. No estado do Rio Grande do Sul, a elevação da produção de lácteos quadruplicou no período analisado, entre 1998 a 2012, segundo dados do IBGE (2012a).

Salienta-se que, assim como a produção, o rebanho leiteiro e a produtividade sofreram alterações positivas e significativas no período analisado, tanto em nível federal quanto estadual, conforme análise dos dados do IBGE (2012a). O impacto que cada variável gera na quantidade total produzida define se está ocorrendo aproveitamento dos recursos ou apenas aumento das matrizes.

Diante desse cenário, o objetivo deste trabalho é analisar os impactos da quantidade de animais, da produtividade e do preço na geração do valor de produção do leite, incidente sobre a taxa de crescimento anual do valor da produção dos maiores municípios que mantêm produção de leite no Rio Grande do Sul. 
A justificativa e a motivação para a realização desta pesquisa estão centradas na necessidade de se conhecer qual variável apresenta maior relevância na definição do valor da produção do leite, pois, com isso, os formadores de políticas terão argumentos para implementar políticas públicas no setor e melhorar os fatores menos relevantes, mantendo o comportamento do fator mais impactante da obtenção do valor da produção do leite.

O artigo será estruturado em cinco seções, cuja seção inicial contextualiza e apresenta a delimitação do problema de pesquisa e seu objetivo. Na seção seguinte consta o referencial teórico necessário para o entendimento do assunto em questão, já na terceira seção demonstra-se a metodologia utilizada para a segregação dos impactos das variáveis consideradas no modelo. Os resultados são apresentados e discutidos na seção quatro e, por fim, na seção cinco, conclui-se com as principais considerações obtidas no estudo.

\section{Referencial teórico}

A indústria de alimentos sempre desempenhou um importante papel na economia brasileira, representando uma das mais tradicionais estruturas produtivas existentes no país. Produtos como soja, milho, trigo, cevada, café, carnes, leite e outros constituem os principais produtos da pauta exportadora e geradora de superávit comercial. No mesmo sentido, o leite tem participação relevante na economia nacional, e cada vez mais aumenta sua participação na pauta de exportação, principalmente na forma de leite em pó, apresentando, com isso, perspectivas significativas para a cadeia leiteira nos próximos anos, em especial com as alterações impostas nos fatores determinantes para comercialização.

As mudanças ocorridas no cenário internacional impactam fortemente a cadeia láctea. Os preços internacionais dos derivados e suas oscilações, as flutuações da taxa de câmbio, assim como a produção nos diferentes países, a oferta e a demanda interna e externa, crises específicas e globais, alteram as negociações, os preços das commodities, os custos, deixando os elos da cadeia em constante alerta e preocupação.

Após ano atípico, com baixo consumo interno e externo e, consequentemente, elevada queda no preço da commodity, o ano de 2007 iniciou-se com uma elevada demanda de leite e derivados, que gerou um aumento de comercialização internacional, portanto, de exportação, de aproximadamente $80 \%$ do leite em pó, entre dezembro de 2006 e novembro de 2007, e os leites UHT e pasteurizado obtiveram valorização elevada no primeiro semestre e uma perda no semestre posterior, em função da elevação dos preços e da oferta. Esse aglomerado de situações gerou ao 
produtor um incremento na receita de $28 \%$, quando comparado ao período anterior, conforme informa o Centro de Estudos Avançados em Economia Aplicada (Cepea) (2010) , da Escola Superior de Agricultura Luiz de Queiroz.

No período de 2009, conforme se observa na Figura 1, houve uma redução expressiva no valor do litro de leite, pois, segundo dados do Cepea (2010), ocorreu um aumento de $81 \%$ nas importações e uma queda de $52,4 \%$ nas exportações nacionais em relação ao ano de 2008. Esse cenário perdurou até novembro de 2009, quando as importações recuaram $32 \%$ em volume, dando sinais de melhora no preço. Contribuindo para isso, houve a desaceleração produtiva na Região Sul, o que auxiliou na melhora do preço no final do período.

No ano de 2010, o preço da commodity permaneceu no mesmo patamar, conforme informações do Cepea (2011a), devido aos baixos estoques desde o período anterior. Verifica-se na análise dos preços pagos ao produtor, deflacionados pelo Índice Nacional de Preços ao Consumidor Amplo de janeiro de 2014, que há uma heterogeneidade em sua disposição pelo tempo. Há uma tendência de alta, visualizando-se, no período compreendido entre janeiro de 2007 a janeiro de 2014, uma variação positiva ao preço pago ao produtor gaúcho, de $71,78 \%$, saltando dos $R \$$ 0,68 para $\mathrm{R} \$ 0,97$ por litro.

Ferreira Júnior e Teixeira (2005) salientam que a relação entre preço e quantidade do produto torna-se importante na mensuração e análise da cadeia láctea pelos setores a montante e a jusante do processo produtivo e para o setor governamental gaúcho.

Figura 1 - Preço pago ao produtor gaúcho de janeiro de 2004 a janeiro de 2014

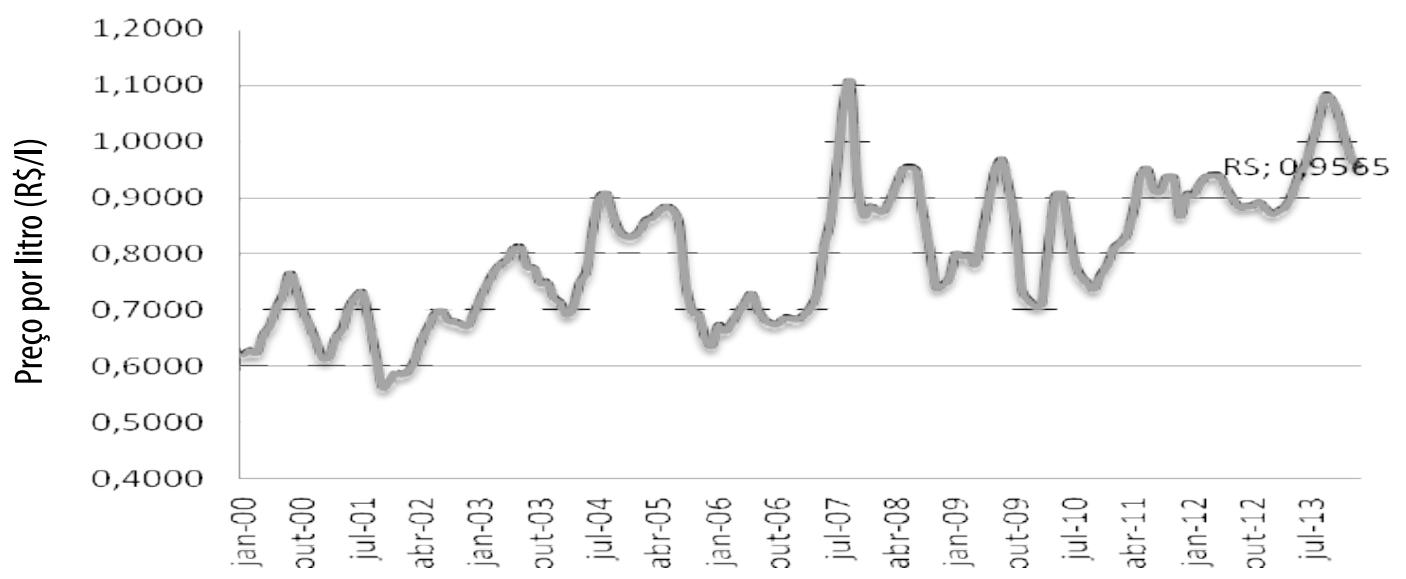

Fonte: Cepea (2014). 
No estado do Rio Grande do Sul, o setor atua de modo a manter a população no campo, pois contribui para o desenvolvimento socioeconômico rural e regional. Os produtores começam a deter maior parcela dos ganhos da cadeia, o que incentiva a produção e reprime o êxodo rural. $O$ estado detém a segunda maior bacia leiteira do país com forte participação de pequenos pecuaristas no setor produtivo, distribuindo renda e melhorando as condições de vida da sociedade.

\subsection{Produção}

A análise dos dados do Instituto Brasileiro de Geografia e Estatística (2012b) permite verificar que a produção nacional da commodity tem tendência de alta. No período analisado, compreendido entre 2002 e 2012, detectou-se uma variação produtiva com crescimento de $49,26 \%$, demonstrando a especialização do setor, uma maior produtividade e, consequentemente, a inserção de uma nova atividade econômica no país. O aumento da produção nacional de leite desenvolve-se por meio da grande participação das Regiões Sudeste e Sul, nas quais estão os maiores produtores nacionais de leite e derivados, assim como as indústrias processadoras.

A Região Sudeste, conforme dados do IBGE (2012b), detém a maior produção nacional, assim como o estado de maior produção: Minas Gerais. Nota-se que a Região Sudeste e o estado de Minas Gerais apresentam variações produtivas semelhantes, denotando forte característica da atividade leiteira no estado mineiro, que respondia, em 2012 , por $76,83 \%$ do total produzido naquela região do país, totalizando um montante de 8.906 milhões de litros frente aos 11.591 milhões produzidos pelo Sudeste. A Região Sul, por sua vez, detém variações intermunicipais mais moderadas. No período analisado, compreendido entre 2002 e 2012 , a região deteve um acumulado produtivo de $94,92 \%$.

Segundo dados do IBGE (2012b), referentes ao ano de 2012, nota-se que o estado do Paraná é responsável por 36,97\% da produção, com 3.968 milhões de litros do total da Região Sul. O Rio Grande do Sul participa com 37,72\% da produção da região, com 4.049 milhões de litros, e Santa Catarina produz 2.717 milhões de litros, com uma participação de $25,31 \%$. Salienta-se que o grande crescimento ocorrido no território catarinense, no período de 2002 a 2012, registrou um aumento de $127,86 \%$ em sua produção, mostrando o fortalecimento estadual da atividade e, concomitantemente, nas demais regiões.

A necessidade de gerenciamento de custos e produção, devido às desvalorizações cambiais nos períodos antecedentes, atrelou uma crescente melhora produtiva no país. No Brasil, a produtividade por vaca, em 2002, chegou a 1.152 litros/ano, 
fechando 2012 em 1.417 litros/ano. Diferente do Rio grande do Sul, onde a produtividade em 2002 já era superior à média nacional de 2012, com 1.964 litros/ano, passando a 2.670 litros/ano em 2012. Assim, mesmo com uma disparidade elevada na produtividade em nível nacional e estadual, o Rio Grande do Sul tem muito a melhorar, já que está distante dos números de produtividade da Europa e dos Estados Unidos da América.

No estado gaúcho, a produção é dinâmica, pois, segundo Barros, Lima e Fernandes (2010), há uma estrutura de mercado atomizada, cuja produção se encontra fragmentada entre os participantes (pequenos, médios e grandes produtores). A participação de grande número de pequenos produtores decorre da rentabilidade que o setor proporciona, efeito decorrente da grande demanda e da baixa oferta do produto e seus derivados.

Por meio da análise dos dados da Fundação de Economia e Estatística Siegfried Emanuel Heuser (FEE) (2013a), reforça-se a afirmação de Barros, Lima e Fernandes (2010), que propõem que a produção leiteira no Rio Grande do Sul manifesta-se como discriminador de renda. Na disposição dos números, observa-se que os dez maiores produtores de leite no ano de 2012 contribuíram com um montante de 468.424 mil litros/ano do total produzido no estado.

Por ser uma atividade desenvolvida essencialmente em pequenas propriedades, ocorre distribuição da renda, principalmente, entre os principais centros produtores. Os maiores municípios produtores de leite do Rio Grande do Sul são Casca, Santo Cristo, Marau, Ijuí, Sananduva, Ibirubá, Três de Maio, Palmeira das Missões, Augusto Pestana e Estrela (IBGE, 2012b), que tiveram, em 2012, uma participação equivalente a $11,57 \%$ do total produzido no estado, seguindo uma tendência ativa, resultante das melhorias no rebanho, da adesão à tecnologia e das estratégias de comercialização, gerando maior rentabilidade ao produtor.

Com uma produtividade de 5.768 litros/ano por cabeça, o município de Casca lidera o ranking de produtividade de leite, apresentando um aumento de produtividade entre 2002 e 2012 de, aproximadamente, 207,47\% (IBGE, 2012b). Casca deteve uma produção de, aproximadamente, 65,2 milhões de litros em 2012, apresentando um aumento produtivo em torno de $431,4 \%$ no período analisado.

Em seguida, encontra-se o município de Santo Cristo com uma produção de 58,2 milhões de litros, elevando sua produção em $211,9 \%$ diante a produção de 27,5 milhões de litros produzidos em 2002. Já os municípios gaúchos Marau e Ijuí, em 2012, produziram 52,7 milhões e 50 milhões de litros, respectivamente. Sananduva tornou-se, em 2012, o município gaúcho com a quinta maior produção láctea primária, com um montante de 43,5 milhões de litros, representando 1,07\% do total produzido no estado. 
Na sequência, encontra-se o município de Ibirubá, com 41,26 milhões de litros de leite, seguido pelo município Três de Maio, com uma produção de 41,21 milhões de litros. Depois, aparece o município de Palmeira das Missões, que ocupa o posto de oitavo maior produtor gaúcho, com 40,2 milhões de litros. Por último, tem-se os municípios Augusto Pestana, que produziu 38 milhões de litros de leite, e Estrela, o décimo maior produtor estadual, com 37,9 milhões de litros.

Esses últimos cinco municípios correspondem a uma participação em âmbito estadual de $1,02 \%, 1,01 \%, 0,99 \%, 0,93 \%$ e 0,93\%, respectivamente. Juntos detêm um percentual de 4,91\% do total produzido no Rio Grande do Sul. Salienta-se o significativo crescimento dessa atividade nos municípios analisados assim como o crescimento da produção estadual do leite.

\subsection{Demanda}

O aumento da demanda doméstica e a falta de qualidade da commodity fazem com que a produção nacional seja insuficiente para o abastecimento e a satisfação da demanda industrial. Nesse sentido, a melhoria da eficiência ao longo da cadeia produtiva, a incorporação de tecnologias no campo e o cenário mundial favorável levaram o país a ser exportador líquido de lácteos. Para isso, foram necessários investimentos no setor a fim de prezar pela qualidade do leite e seus derivados.

Diante disso, o consumo aparente nacional cresce em ritmo superior ao da produção, ocasionando a elevação dos preços e, consequentemente, um contínuo aumento produtivo, visto que o pecuarista terá maiores incentivos e melhores lucros. A elevação de consumo aparente, entre 2006 e 2011, apresentou variação positiva de 21,8\% (IBGE, 2012a).O consumo aparente per capita de lácteos nacionais elevou-se entre 2001 e 2011 em 15,3\%, passando para um consumo de 159,76 quilogramas/ano em 2011. Em 2007, o consumo atingiu 145,18 quilogramas/ano, com uma variação positiva de $4,8 \%$. Nos períodos subsequentes, exceto em 2011, o aumento variou apenas $1,6 \%$ em relação ao ano anterior, atingindo um consumo per capita de 159,76 quilogramas/ano, a variação deu-se contínua e constantemente em 2,7\%, atingindo um consumo de 157,28 quilogramas/ano em 2010 (IBGE, 2012a).

Um fato relevante na cadeia láctea nacional, conforme descrevem Ponchio e Silva (2005), deu-se pelo aumento da demanda interna de lácteos em 2004, que absorveu o aumento da oferta de $2,8 \%$. O aquecimento da demanda interna juntamente com o novo desempenho externo, elevação das exportações e superávit comercial, proporcionou um acréscimo no preço da commodity ao produtor. 
O consumo aparente per capita gaúcho (FEE, 2013b) encontra-se elevado, se comparado com o consumo aparente nacional. Em 2001, a população gaúcha consumia 206 quilogramas/ano, chegando a um consumo de 321 quilogramas/ano em 2010, um aumento de 55,82\%. Mas, apesar de o consumo aparente no Rio Grande do Sul se encontrar em tendência de alta, não há homogeneidade. O aumento da produção estadual no período foi de $63,5 \%$. As exportações elevaram-se $92,2 \%$ e as importações variaram $-68,4 \%$, ou seja, as importações diminuíram em relação a 2001.

Desse modo, nota-se a importância que a produção gaúcha de lácteos exerce no estado. $\mathrm{O}$ aumento do consumo aparente, conforme análise total entre o período inicial e final, é sustentado pela produção interna, em que o aumento das exportações e a redução das importações afetam negativamente o consumo aparente.

\section{Metodologia}

Na posição de segundo maior produtor nacional de lácteos, o Rio Grande do Sul obteve aumentos produtivos e consequente melhoria qualitativa e produtiva. Assim, pretende-se analisar, no período de 2002 a 2012, quais os fatores que mais contribuíram para o valor da produção do estado e dos maiores municípios produtores de leite.

Utilizando metodologia similar ao estudo realizado por Bastos e Veggiano (2014) para Minas Gerais, o método diferencial-estrutural possibilita uma análise individual e global das variáveis rebanho $(\mathrm{A})$, produtividade $(\mathrm{R})$ e preço $(\mathrm{P})$, no movimento do valor da produção leiteira estadual e municipal.

Esse modelo é decomposto em três efeitos: o efeito rebanho, causado pela variação nos números de animais ordenhados, o efeito produtividade, no qual consta a modificação na produtividade láctea por meio das novas tecnologias e da implantação de genética no rebanho da propriedade, e, por fim, o efeito preço, analisado sobre o valor da produção.

Por isso, trata-se de uma pesquisa descritiva com análise de dados secundários, em que as séries sobre rebanho leiteiro (número de cabeças/ano), preço médio do leite ( $\mathrm{R} \$$ /litro), produtividade (litros de leite/animal) e quantidade produzida (litros de leite/ano), na esfera estadual e nos municípios analisados, provêm da base de dados da Fundação de Economia e Estatística (2013s). O valor da produção ( $R$ / ano) para o estado e os municípios foi identificado por meio do Instituto Brasileiro de Geografia e Estatística (2012b) para o período compreendido entre 2002 e 2012. 


\subsection{Modelo empírico}

O modelo shift-share compreende uma análise estatística que pode ser utilizada em diversos campos de conhecimento. Essa análise realiza a decomposição das taxas de variação em fontes de conhecimento, ou seja, busca ilustrar o comportamento da produção agrícola mediante a decomposição dos fatores responsáveis pela variação da produção.

Para separar os efeitos rebanho, produtividade e preço da taxa de crescimento do valor da produção do leite, utilizou-se o modelo shift-share, também conhecido como modelo diferencial-estrutural. Assim, poder-se-á estimar a importância relativa de cada um dos componentes sobre os acréscimos ou decréscimos no valor da produção.

O modelo shift-share busca averiguar a variação entre dois pontos, normalmente em base anual, sendo que se determina como período inicial $\left(t_{0}\right)$ e período final $\left(t_{1}\right)$. Assim, o valor da produção leiteira pode ser definido para o período inicial por:

$$
V t_{0}=A t_{0} R t_{0} P t_{0}
$$

E para o período final como:

$$
V t_{1}=A t_{1} R t_{1} P t_{1}
$$

Em que $V$ representa o valor da produção leiteira $(\mathrm{R} \$), A$ mostra o rebanho utilizado para produção leiteira (animais), $R$ apresenta a produtividade do rebanho (litros/animal), e $P$ é o preço médio do leite pago ao produtor ( $\$$ /litro). Considerando-se uma variação no rebanho leiteiro no período $t_{1}$, o valor da produção passaria a ser computado da seguinte maneira:

$$
V^{A} t_{1}=A t_{1} R t_{0} P t_{0}
$$

Se a variação no período $t_{1}$ ocorresse no rebanho e na produtividade, mantendo-se constante o preço, o valor da produção seria dado por: 


$$
V^{A R} t_{1}=A t_{1} R t_{1} P t_{0}
$$

A variação total no valor da produção entre os períodos $t_{0}$ e $t_{1}$ seria dada pela Equação 5 ou pela Equação 6.

$$
\begin{gathered}
V t_{1}-V t_{0}=\left(A t_{1} R t_{1} P t_{1}\right)-\left(A t_{0} R t_{0} P t_{0}\right) \\
V t_{1}-V t_{0}=\left(V t_{1}^{A}-V t_{0}\right)+\left(V t_{1}^{A R}-V t_{1}^{A}\right)+\left(V t_{1}-V t_{1}^{A R}\right)
\end{gathered}
$$

Em que $V t_{1}-V t_{0}$ é a variação total no valor da produção, $V t_{1}^{A}-V t_{0}$ mostra o efeito rebanho, $V t_{1}^{A R}-V t_{1}^{A}$ representa o efeito rendimento, e $V t_{1}-V t_{1}^{A R}$ capta o efeito preço.

Os efeitos explicativos podem ser convertidos na forma de taxas anuais de crescimento, que, somadas, resultam na taxa anual de variação do valor da produção. Assim, tem-se:

$$
V=\frac{\left(V t_{1}^{A}-V t_{0}\right)}{\left(V t_{1}-V t_{0}\right)}+\frac{\left(V t_{1}^{A R}-V t_{1}^{A}\right)}{\left(V t_{1}-V t_{0}\right)}+\frac{\left(V t_{1}-V t_{1}^{A R}\right)}{\left(V t_{1}-V t_{0}\right)}
$$

Para se obter a taxa de crescimento entre dois períodos ( $r$, pode-se usar:

$$
r=\left(\sqrt[t]{V t_{1} / V t_{0}-1}\right) 100
$$

Realizando-se a multiplicação da Equação 7 pela taxa de crescimento entre os períodos $(r)$, obtêm-se os efeitos rebanho, produtividade e preço expressos em porcentagens ao ano, conforme Equação 9.

$$
V=\left[\frac{\left(V t_{1}^{A}-V t_{0}\right)}{\left(V t_{1}-V t_{0}\right)}\right] r+\left[\frac{\left(V t_{1}^{A R}-V t_{1}^{A}\right)}{\left(V t_{1}-V t_{0}\right)}\right] r+\left[\frac{\left(V t_{1}-V t_{1}^{A R}\right)}{\left(V t_{1}-V t_{0}\right)}\right] r
$$

Dessa forma, decompõem-se os diferentes efeitos que serão expressos em taxa de crescimento anual (\%): 
Efeito rebanho $=\quad\left[\frac{\left(V t_{1}^{A}-V t_{0}\right)}{\left(V t_{1}-V t_{0}\right)}\right] r$

Efeito produtividade $=\left[\frac{\left(V t_{1}^{A R}-V t_{1}^{A}\right)}{\left(V t_{1}-V t_{0}\right)}\right] r$

Efeito preço $=\quad\left[\frac{\left(V t_{1}-V t_{1}^{A R}\right)}{\left(V t_{1}-V t_{0}\right)}\right] r$

Entretanto, segundo Pospiesz, Souza e Oliveira (2011), o modelo shift-share apresenta algumas limitações que precisam ser levadas em consideração: a) poderão ocorrer mudanças nas variáveis econômicas no decorrer da análise; b) a análise das diferenças entre regiões torna-se instável a essas mudanças; c) poderá haver dificuldades em separar os diferentes efeitos. Além disso, trata-se de uma ferramenta descritiva, necessitando ainda de uma posterior análise para que se chegue a explicações mais precisas da realidade.

Com uma análise diferente da utilizada neste artigo, Fernandes e Cunha (2011) aplicam o método shift-share visando compreender e explicar as transformações ocorridas no mercado formal de trabalho paranaense, compreendendo um período de dez anos (1996 a 2006). Por meio da pesquisa e apreciação dos dados, os autores apontam que na década de 1990, na região metropolitana, a alocação formal de profissionais ficou mais moderada se comparada com a década seguinte. No entanto, incidiu uma despolarização do emprego, ocorrendo um aumento empregatício formal no interior, promovido pela indústria de alimentos, bebidas, álcool etílico e têxtil, que resultou em um incremento motivacional e, consequentemente, geração de postos de trabalho pelo aumento da riqueza e melhores condições de vida na região não metropolitana. Os autores relatam que o emprego no setor de serviço aumentou na região metropolitana, melhoria causada pela diversificação das atividades.

Um estudo similar, de Souza e Souza (2004), no Rio grande do Sul, analisou a dinâmica do crescimento do emprego na Região Metropolitana de Porto Alegre e seus municípios, no período compreendido entre 1990 e 2000. Por meio da análise, os autores aferiram que a demanda por colaboradores em vários setores da economia deslocou-se para o interior do estado, para a periferia da metrópole e para outras regiões do Brasil. Alguns motivos relacionados e situados no estudo mostram que a demanda global descentralizou-se da Região Metropolitana de Porto Alegre. 
A busca por vantagens locacionais, menores custos e novos nichos de mercado fez com que a indústria migrasse para regiões periféricas.

Outro estudo, realizado por Magrini e Canever (2003), utilizando o método shift-share, buscou analisar o valor anual da produção orizícola gaúcha entre os anos de 1975 e 2001, verificando como a área, o rendimento e o preço influenciaram nas oscilações da produção de arroz do estado. Os autores verificaram o aumento do valor anual da produção até 1986, após, houve uma instabilidade que perdurou cinco anos. Depois desse período, percebeu-se uma queda no restante dos anos. As variações ocorridas, segundo os autores, foram implicadas, principalmente, por oscilações dos preços.

Visando à análise das fontes de crescimento da pecuária leiteira em Minas Gerais, Bastos e Veggiano (2010) aplicaram o método diferencial-estrutural para o período compreendido entre 1997 e 2010. Com a pesquisa, os autores avaliaram as oscilações na produção, levando em conta o aumento da produtividade ou do rebanho produtor. Eles concluíram que o aumento da produção retrocede o aumento do rebanho, o que, segundo os autores, implica em um maior custo e diminui a sustentabilidade da produção. Por isso, salientam a importância do incremento de tecnologia e genética para uma produtividade maior e de qualidade.

\section{Resultados e discussão}

As evoluções observadas no setor lácteo brasileiro nos últimos anos elevaram a competitividade do setor. Nesse contexto, foram analisados os impactos da quantidade de animais, da produtividade e do preço na geração do valor de produção do leite, incidente sobre a taxa de crescimento anual do valor da produção estadual nos maiores municípios produtores de leite do Rio Grande do Sul.

Essa análise demonstrou que o constante aumento produtivo do estado e dos municípios é atribuído às melhorias impostas pelo pecuarista e pelo mercado, que exige maiores aproveitamento e qualidade na produção.

Assim sendo, na Tabela 1, apresenta-se a participação e contribuição das variáveis explicativas que inferem sobre o valor da produção. Aplicando-se o modelo shift-share, obteve-se um incremento no valor da produção estadual de 142,70\%, com a decomposição em três efeitos, em que o efeito rebanho incrementa 19,52\% na variação do valor da produção, o efeito produtividade acrescenta $32,22 \%$, e o efeito preço atua como o maior motivo do aumento do valor da produção, adicionando ao crescimento $90,97 \%$. 
Tabela 1 - Taxas médias anuais de crescimento do valor da produção de leite no período de 2002 a 2012 (\%)

\begin{tabular}{l|c|c|c|c}
\cline { 2 - 4 } & Valor da produção & Rebanho & Produtividade & Preço \\
\hline Rio Grande do Sul & 142,70 & 19,52 & 32,22 & 90,97 \\
Augusto Pestana & 102,51 & $-6,10$ & 53,35 & 55,26 \\
Casca & 140,97 & 13,83 & 67,81 & 59,33 \\
Estrela & 106,97 & 4,18 & 37,97 & 64,83 \\
Ibirubá & 123,16 & $-6,88$ & 15,22 & 114,82 \\
ljuí & 100,37 & $-8,21$ & 51,21 & 57,37 \\
Marau & 155,46 & 23,59 & 68,38 & 63,49 \\
Palmeira das Missões & 117,74 & $-19,78$ & 55,09 & 82,43 \\
Sananduva & 117,21 & 1,09 & 28,80 & 87,32 \\
Santo Cristo & 107,54 & $-17,79$ & 50,06 & 75,27 \\
Três de Maio & 100,01 & $-24,99$ & 48,47 & 76,53 \\
\hline
\end{tabular}

Fonte: elaboração das autoras com base em dados da FEE (2013b) e do IBGE (2013b).

A proporção na participação de cada efeito na taxa de crescimento do valor da produção corresponde a $13,68 \%$ do efeito rebanho e $22,58 \%$ do efeito produtividade, apresentando uma diferença no crescimento de 8,9 pontos percentuais. $O$ efeito preço, contudo, detém a maior participação, com 63,74\%. Diante disso, denota-se que o aumento do efeito rebanho, em tal proporção, 19,52\%, e da produtividade, em $32,22 \%$, implica um baixo aproveitamento na cadeia. Mesmo com a melhora da produtividade, o efeito preço apresenta uma importância significativa, deixando a cadeia vulnerável às oscilações do mercado e, concomitantemente, expondo os setores produtivos aos riscos externos e internos.

Analisando os dados do rebanho lácteo disponíveis no banco de dados da FEE (2013b), verificou-se que em 2002 o rebanho leiteiro gaúcho era de 1.186 .301 cabeças, saltando para 1.516.689 cabeças em 2012, correspondendo a um aumento de $27,85 \%$. Observa-se, também, que a quantidade de leite produzida no estado elevou-se de 2.329 milhões de litros para 4.049 milhões de litros ao ano, um aumento de $73,85 \%$ no período compreendido entre 2002 e 2012, correspondendo a 1.720 milhões de litros. Contudo, a produtividade gaúcha elevou-se 35,94\%, passando de 1.964 litros/ano/vaca, em 2002, para 2.670 litros/ano/vaca, em 2012.

Segundo Finamore e Montoya (2005), as mudanças estruturais propiciaram ganhos de produtividade no setor lácteo, e a integração da indústria com o produtor propiciou melhoramento produtivo e qualitativo, dinamizando a produção láctea gaúcha. 
Barros, Lima e Fernandes (2010) afirmam que a produção gaúcha encontra-se distribuída, em grande parte, entre pequenos pecuaristas, que veem na atividade um complemento para a renda ou, até mesmo, em caso de atividade principal, um maior aproveitamento produtivo, visto que se compreende que as pequenas propriedades necessitam de organização territorial e elevada produtividade por hectare. Essa dedicação incide no melhoramento qualitativo e produtivo da produção láctea do estado, que deve aproveitar a demanda aquecida e a baixa qualidade do produto em outros mercados para melhorar sua competitividade nacional e internacionalmente.

A análise dos dados da FEE (2013b) apresenta, reforçando a posição de Barros, Lima e Fernandes (2010) com relação à descentralização produtiva da cadeia láctea, a participação dos dez municípios que contam com as maiores quantidades produzidas de leite, aquém a um percentual de $11,57 \%$, em 2012, que tiveram um aumento de 3,24 pontos percentuais em relação ao período de 2002. Constata-se que, do acréscimo auferido no decorrer do período, equivalente a 1.720 milhões de litros, o aumento do rebanho foi de 330.388 cabeças, com uma elevação para 706 litros/ano/vaca. Assim, o crescimento analisado apresenta-se, em relação à produtividade, aquém em relação ao aumento do rebanho, visto que o aproveitamento do capital produtivo encontra-se distante dos rendimentos produtivos norte-americanos e europeus.

Segundo dados do Cepea (2014), no período de 2012, o custo operacional efetivo no Rio Grande do Sul, ou seja, o custo do proprietário com alimentação, manejo, cuidados, funcionários e outras despesas, aumentou significativamente, juntamente a isso, a diminuição de $6 \%$ nas exportações nacionais e a diferença de $20 \%$ a $30 \%$ entre a commodity nacional e a importada da Argentina fez com que se elevassem as importações. Os altos preços nacionais baixam a competitividade no mercado internacional.

A dependência, identificada na análise do efeito preço em um mercado competitivo como esse em que a cadeia encontra-se inserida, exige o máximo aproveitamento dos recursos, inclusive com investimentos em genética e tecnologias que possam melhorar a produtividade do rebanho, reduzindo a proporção do efeito preço sobre a taxa de crescimento do valor da produção e fortalecendo os setores produtivos, industriais e de serviços, protegendo-os das oscilações mercadológicas.

Segundo Ponchio e Silva (2005), o aumento do consumo nacional e a contínua elevação dos volumes exportados alteraram a diferença entre a oferta e a demanda do produto e, consequentemente, ocasionaram uma elevação nos preços da commodity. As retrações do mercado com a crise internacional e a valorização cambial prejudicaram as exportações, no entanto, o mercado interno vem suprindo a produção, mantendo o preço nos patamares atuais. 
Analisando especificamente os maiores municípios do estado, verificou-se que o município de Augusto Pestana, obteve um efeito produção de 102,51\%, atribuindo uma participação de $53,35 \%$ ao efeito produtividade, $55,33 \%$ ao efeito preço e $-6,10 \%$ ao efeito rebanho. Nota-se, que a participação do efeito preço e do efeito produtividade foi de igual intensidade, comparados ao efeito rebanho, que teve uma redução. Isso demonstra a especialização no município e a valorização do produto. Portanto, o aumento do valor da produção foi ocasionado, principalmente, pelo aumento da produtividade, sendo que o rebanho, inclusive, apresentou redução no período analisado.

O município de Casca, detentor da maior produção do estado, obteve um efeito rebanho de $13,83 \%$, seguido de $67,81 \%$ e 59,33\% para os efeitos produtividade e preço, respectivamente, totalizando um efeito valor de produção de $140,97 \%$. Isso mostra, em ordem participativa, que a produtividade seguida do preço e, posteriormente, do rebanho inferem no acumulado no efeito valor da produção.

Com um valor da produção de 106,97\%, o município de Estrela subdivide esse efeito em $4,18 \%$, correspondendo ao efeito rebanho, $37,97 \%$, ao efeito produtividade, e o restante, compreendendo $64,83 \%$, ao efeito preço.

Salienta-se a semelhança nos efeitos para os municípios de Palmeira das Missões, Santo Cristo e Três de Maio, que obtiveram efeitos negativos de dois dígitos no rebanho, de -19,78\%, -17,79\% e -24,99\%, respectivamente. Em Três de Maio, o efeito rebanho foi mais retraído. Os municípios têm, respectivamente, um efeito valor de produção de $117,74 \%, 107,54 \%$ e 100,01\%.

Tabela 1 - Taxas médias anuais de crescimento do valor da produção de leite no período de 2002 a 2012 (\%)

\begin{tabular}{l|c|c|c|c}
\hline & Valor da produção & Rebanho & Produtividade & Preço \\
\hline Rio Grande do Sul & 142,70 & 19,52 & 32,22 & 90,97 \\
Augusto Pestana & 102,51 & $-6,10$ & 53,35 & 55,26 \\
Casca & 140,97 & 13,83 & 67,81 & 59,33 \\
Estrela & 106,97 & 4,18 & 37,97 & 64,83 \\
Ibirubá & 123,16 & $-6,88$ & 15,22 & 114,82 \\
ljuí & 100,37 & $-8,21$ & 51,21 & 57,37 \\
Marau & 155,46 & 23,59 & 68,38 & 63,49 \\
Palmeira das Missões & 117,74 & $-19,78$ & 55,09 & 82,43 \\
Sananduva & 117,21 & 1,09 & 28,80 & 87,32 \\
Santo Cristo & 107,54 & $-17,79$ & 50,06 & 75,27 \\
Três de Maio & 100,01 & $-24,99$ & 48,47 & 76,53 \\
\hline
\end{tabular}

Fonte: elaboração das autoras com base em dados da FEE (2013b) e do IBGE (2013b). 
Os efeitos produtividade e preço correspondem, respectivamente, a 55,09\% e $82,43 \%$ no município de Palmeira das Missões. No município de Santo Cristo, os efeitos deram-se em $50,06 \%$ e $75,27 \%$, respectivamente, já no município de Três de Maio, $48,47 \%$ correspondem ao efeito produtividade e 76,53\% ao efeito preço. Nota-se certa homogeneidade, nas participações das oscilações individuais, em que o preço e a produtividade tiveram um aumento significativo, considerando a supressão do efeito rebanho no montante de cada município.

Com um efeito valor de produção de $117,21 \%$, próximo aos números dos municípios recém-relacionados, Sananduva distribui uma porção de 1,09\% ao efeito rebanho, $28,80 \%$ ao efeito produtividade e $87,32 \%$ ao efeito preço. Verifica-se a diferença participativa dos efeitos individuais no efeito total do município, sendo que o efeito preço corresponde a uma participação de 74,50\% no efeito total, seguido da participação equivalente a $24,57 \%$ do efeito produtividade e apenas $0,93 \%$ do efeito rebanho.

No município de Ibirubá, o efeito total soma $123,16 \%$, sendo que o efeito preço é de $114,82 \%$, ou seja, constitui-se na maior participação no efeito total dos municípios analisados. Posteriormente, o efeito produtividade mostra 15,22\%, e o efeito rebanho $-6,88 \%$. Nota-se que o valor da produção no município de Ibirubá encontra-se mais nas forças de mercado do que no potencial produtivo municipal, desse modo, uma análise setorial para tomar as corretas concepções faz-se necessária.

Analisando os dados de Ijuí, verificou-se um efeito produção de 100,37\%, com $-8,21 \%$ referente ao efeito rebanho, $51,21 \%$, ao efeito produtividade, e $57,37 \%$, ao efeito preço. Identifica-se uma queda no efeito rebanho e uma consequente melhoria nos demais efeitos, sendo a produtividade principal fator no processo produtivo.

O município de Marau obteve um efeito valor de produção de 155,46\%, atribuído às somas dos efeitos rebanho, com 23,59\%, produtividade, com 68,38\%, e o restante, $63,49 \%$, atribuído ao efeito preço. Verifica-se que o efeito produtividade tem uma magnitude um pouco maior no valor da produção do que o efeito preço, no entanto, salienta-se a grande porção ocupada pelo efeito rebanho.

Em uma visão geral, nota-se que o valor da produção destacou-se nos municípios de Marau, Casca e Ibirubá. Já o efeito rebanho incidiu mais nos municípios de Marau e Casca, que obtiveram efeitos de produtividade mais elevados e, por fim, o efeito preço, que foi o que mais influenciou no valor da produção, nos municípios de Ibirubá e Sananduva.

Analisando-se a taxa anual de crescimento, verifica-se que apenas o município de Marau $(155,46 \%)$ obteve uma taxa maior que o crescimento estadual (142,70\%), impulsionado pelos efeitos rebanho, 23,59\%, e produtividade, $68,38 \%$, 
que se sobressaíram aos efeitos estaduais, $19,52 \%$ e $90,97 \%$, respectivamente, e também pelo efeito preço, de $63,49 \%$, aquém do efeito preço no estado, equivalente a $90,97 \%$.

Dos municípios analisados, verifica-se que apenas Ibirubá e Sananduva atribuem efeito produtividade, correspondente a $15,22 \%$ e $28,80 \%$, respectivamente, inferior ao obtido pelo estado, que foi de $32,22 \%$. E, em relação ao efeito preço, apenas o município de Ibirubá apresenta valor superior ao estadual, de 114,82\% para $90,97 \%$.

Aproveitando os rendimentos obtidos com a commodity, visualiza-se o aumento do rebanho, em particular, nos municípios de Marau e Casca, que obtiveram efeitos consideráveis, de $23,59 \%$ e $13,83 \%$, respectivamente. $\mathrm{E}$ o aumento do efeito produtividade, em que se observa o melhor aproveitamento e os maiores rendimentos da cadeia, acresceu a margem lucrativa da propriedade, proporcionando renda para melhoramentos tecnológicos, genéticos e, consequentemente, avanços na qualidade e produtividade. Exemplos disso são os municípios de Marau e Casca, com um efeito de $68,38 \%$ e $67,81 \%$, respectivamente.

Salienta-se que, conforme análise dos dados da FEE (2013b), quanto à quantidade de vacas ordenhadas, na pesquisa municipal no estado do Rio Grande do Sul, verificou-se uma redução de $5 \%$ no rebanho lácteo, em relação aos dez municípios que se destacam na produção, demonstrando uma vantagem competitiva sobre os demais municípios gaúchos.

Enfim, os elevados efeitos dos preços que incidem na maior parte dos municípios podem decorrer, principalmente, pela demanda aquecida, ressaltando-se o consumo interno, que vem aumentando em proporções maiores do que a produção nacional, agregando, com isso, valor e qualidade à cadeia leiteira do estado, o que favorece a saída do produto para o mercado internacional.

\section{Considerações finais}

Com a pesquisa realizada, foi possível constatar que o aumento no valor da produção da cadeia do leite no estado do Rio Grande do Sul e nos principais municípios produtores indica que os ganhos de produtividade foram, na maioria das cidades, superiores ao efeito de aumento do rebanho. Além disso, as oscilações dos preços, captadas pelo efeito preço, demonstram que o valor da produção também teve significativa influência dessa variável nominal. Nesse caso, esperava-se maior dependência da produção a variável preço, entretanto, os ganhos obtidos com a 
produtividade são os maiores motivadores do avanço percebido na produção de lácteos no estado.

Os maiores municípios produtores de leite apresentaram efeitos mais destacados em relação aos valores do estado. Nesse sentido, destaca-se o efeito produtividade de Marau e Casca, os maiores dentre os municípios analisados. Isso demonstra que se tornaram grandes produtores de leite não por meio do aumento do rebanho, que também cresceu, mas pelo avanço da tecnologia que possibilitou ganhos significativos de produtividade.

Além disso, essas duas regiões tornaram-se bacias leiteiras com potencial de crescimento devido aos investimentos realizados na qualidade dos animais. Os preços também foram favoráveis para os produtores, visto que cresceram nominalmente nos últimos anos e instigam os produtores de leite a produzir cada vez mais, com bons investimentos em tecnologia e genética.

Portanto, os efeitos preço e produtividade foram os mais destacados, pois o preço é sempre um dos fatores mais importantes, e precisa ser acompanhado para que se possa manter a atividade econômica e a produtividade, que exerce papel fundamental no aumento da produção de alimentos. 


\title{
Analysis of changes in price and milk productivity in Rio Grande do Sul state, Brazil
}

\begin{abstract}
The paper analyzes the impacts of the number of animals, productivity and price in the generation of milk production value, calculated on the annual growth rate of the value of state production and even in major milk producing cities of Rio Grande do Sul State. For this, we used the structural-differential method known as method Shift share effects with production data (FEE, 2014), productivity (FEE, 2014), the price of milk (Cepea, 2014) and production value (FEE, 2014). Thus, it was found that the price effect is largely responsible for the increased growth rate, provided by the continued rise in commodity. However, the productivity effect plays an important role in the milk supply seen in the market that showed superior and significant effect to that seen in the cattle. Thus, there is an increase in milk production was also increased the number of cattle, but more intensely by productivity gains that were perceived among the analyzed period.
\end{abstract}

Keywords: Milk. Cattle. Productivity. Price. Shift Share.

\section{Análisis de los cambios en precio y productividad de leche en del estado Rio Grande do Sul/Brasil}

\section{Resumen}

El trabajo analiza el impacto de la cantidad de animales, la productividad y el precio en la generación de valor de la producción de leche, calculado sobre la tasa de crecimiento anual del valor de la producción de Estado e en los principales municipios productores de leche del Rio Grande do Sul. Por lo tanto, se utilizó el método estructural-diferencial conocido como Shift-share con los datos de producción (FEE, 2014), la productividad (FEE, 2014), el precio de la leche (Cepea, 2014) y valor de la producción (FEE, 2014). Por lo tanto, se encontró que el efecto precio es en gran parte responsable de la mayor tasa de crecimiento, suministrado por el continuo aumento de los productos básicos. Sin embargo, el efecto de la productividad juega un papel importante en el suministro de leche visto en el mercado que mostró un efecto superior y significativo a la observada en el rebaño. Por lo tanto, se observa que el aumento de la producción de leche fue aumentando el rebaño, pero con mayor intensidad por las ganancias de productividad que se percibían entre el período analizado.

Palabras clave: Leche. Rebaño. Productividad. Precios. Shift-share. 


\section{Referências}

BARROS, Fabiano Luiz Alves; LIMA, João Ricardo Ferreira de; FERNANDES, Rosangela Aparecida Soares. Análise da estrutura de mercado na cadeia produtiva do leite no período de 1998 a 2008. Revista de Economia e Agronegócio, Viçosa, v. 8, n. 2, p. 177-198, 2010.

BASTOS, Suzana Quinet de Andrade; VEGGIANO, Leonardo Cordeiro de Farias. Fontes de crescimento da pecuária leiteira: uma análise para o estado de Minas Gerais. Revista de Economia Aplicada, Juiz de Fora, 2014, v. 8, n. 2, 2010.

CENTRO DE ESTUDOS AVANÇADOS EM ECONOMIA APLICADA . Escola Superior de Agricultura Luiz de Queiroz. PIB do Agronegócio. São Paulo, p. 1, 2011a. Disponível em: <http:// cepea.esalq.usp.br/pib/>. Acesso em: 5 set. 2013.

Leite, preços ao produtor. 2014. Disponível em: <http://cepea.esalq.usp.br/leite/?page= 155>. Acesso em : 7 abr. 2014.

. Ano termina com "exportação de 2004" e "importação de 2001". Boletim do Leite Cepea, São Paulo, a. 16, n. 183, p. 4, jan. 2010. Disponível em: <http://www.cepea.esalq.usp.br/leite/ boletim/183.pdf>. Acesso em: 30 jan. 2014.

Mercado internacional: preços externos começam $2011 \mathrm{em}$ forte alta. Boletim do Leite Cepea, São Paulo, a. 17, n. 193, p. 4, jan. 2011b. Disponível em: <http://www.cepea.esalq.usp.br/ leite/boletim/193.pdf>. Acesso em: 30 jan. 2014.

FERNANDES, Carlândia Brito Santos; CUNHA, Marina Silva da. As transformações recentes no mercado de trabalho paranaense: uma aplicação do método shift-share. Revista de Economia - UFPR, Curitiba, a. 35, v. 37, n. 1, p. 149-168, jan./abr. 2011.

FERREIRA JÚNIOR, Sílvio; TEIXEIRA, Erly Cardoso. Relações de produção na pecuária leiteira: um estudo de caso das respostas da produção aos preços mensais. Revista de Economia e Agronegócio, Viçosa, v. 3, n. 2, p. 193-212, 2005.

FINAMORE, Eduardo Belisário; MONTOYA, Marco Antonio. Dimensão econômica do complexo lácteo gaúcho. Revista de Economia e Agronegócio, Viçosa, v. 3, n. 2, p. 213-250, 2005.

FUNDAÇÃO DE ECONOMIA E ESTATÍSTICA SIEGFRIED EMANUEL HEUSER. População. População total do RS por faixa etária e sexo, 2000 a 2011. Data de publicação das informações ?. Disponível em: <http://www.fee.tche.br/sitefee/pt/content/estatisticas/pg_populacao.php>. Acesso em: 15 nov. 2013a.

. Feedados. Dados anuais por variável: Pecuária de leite. Quantidade produzida por município, 2002 a 2012. 2013b. Disponível em: <http://www.fee.rs.gov.br/feedados/consulta/frame_ ResultadoVar.asp >. Acesso em: 17 nov. 2013.

INSTITUTO BRASILEIRO DE GEOGRAFIA E ESTATÍSTICA. Vacas ordenhadas. Pesquisa de pecuária municipal (PPM). Tabela 94. 2012a. Disponível em: <http://www.sidra.ibge.gov.br/bda/ Tabela/protabl.asp?c=94\&z=p\&o=34\&i=P >. Acesso em: 12 mar. 2014.

. Produção de origem animal por tipo de produto. Banco de dados agregados (Sidra), Tabela 74. 2012b. Disponível em: <http://www.sidra.ibge.gov.br/bda/Tabela/protabl. asp?c=74\&z=t\&o=24\&i=P>. Acesso em: 12 mar. 2014. 
MAGRINI, Jeverson L.; CANEVER, Mario D. O valor da produção da orizicultura gaúcha: componentes área, produtividade e preço. Revista Brasileira de Agrociência, Pelotas, v. 9, n. 1, p. 65-69, jan./mar. 2003.

MARION FILHO, Pascoal José; FAGUNDES, Jones de Oliveira; SCHUMACHER, Gabriela. A produção de leite no Rio Grande do Sul: produtividade, especialização e concentração (19902009). Revista de Economia e Agronegócio, Viçosa, v. 9, n. 2, p. 233-252, 2011.

PONCHIO, Leandro Augusto; SILVA, Ana Paula. Pecuária leiteira surpreende em 2004. Boletim do Leite Cepea, São Paulo, a. 11, n. 129, p. 3-5, jan. 2005.

POSPIESZ, Rafaele Cristine; SOUZA, Mario Romero Pellegrini de; OLIVEIRA, Gilson Batista de. Análise shift-share: um estudo sobre os estados da região sul de 2005-2008. Caderno de Iniciação Científica - FAE Centro Universitário, Curitiba, v. 1, p. 327-338, 2011.

SOUZA, Nali de Jesus de; SOUZA, Romina Batista de Lucena de. Dinâmica estrutural-diferencial da região metropolitana de Porto Alegre, 1990/2000. Economia, Curitiba, v. 30, n. 2, p. 121-144, jul./dez. 2004.

EMBRAPA. EMPRESA BRASILEIRA DE PESQUISA AGROPECUÁRIA. Leite inspecionado no Brasil, 2000/2010. Fev. 2012. Disponível em: <http://www.cnpgl.embrapa.br/nova/informacoes/ estatisticas/producao/Tabela0231.php>. Acesso: 10 out. 2013.

IPEADATA - Instituto de Pesquisa Econômica Aplicada. Macroeconômico, população residente. 2014. Disponível em: <http://www.ipeadata.gov.br/>. Acesso em: 20 jan. 2014.

. Índice de Preços ao Consumidor amplo (IPCA) (dez. 1993 = 100). 2012. Disponível em: $\overline{<h t t p / /: w w w . i p e a d a t a . g o v . b r>. ~ A c e s s o ~ e m: ~} 05$ nov. 2012.

LEITE BRASIL - Associação brasileira dos produtores de leite. Ranking maiores laticínios do Brasil, 2011. Disponível em: <http://www.leitebrasil.org.br/DOWNLOAD/maiores\%20laticinios\%20do\%20Brasil\%202011.pdf>. Acesso em: 28 nov. 2013.

MAPA - Ministério da Agricultura, Pecuária e Abastecimento. Instrução normativa ${ }^{\circ}$ 51, de 18 de setembro de 2002. Legislação Agrícola Federal; Brasília, p. 1, 2003. Disponível em:<http:// extranet.agricultura.gov.br/sislegisconsulta/consultarLegislacao.do?operacao=visualizar\& id=8932>. Acesso em: 15 jan. 2014.

Estatísticas de comércio exterior. 2012. Disponível em: <http://www.agricultura.gov.br/ internacional/indicadores-e-estatisticas/informes-de-produtos $>$. Acesso em: 15 fev. 2014.

MDIC - Ministério do Desenvolvimento, Indústria e Comércio Exterior. Exportação 1997-2012 NCM 8 dígitos. Aliceweb2, 2012. Disponível em:<http://aliceweb2.mdic.gov.br//consulta-ncm/index/type/exportacaoNcm> Acesso em: 15 fev. 2014.

. Importações 1997-2012 NCM 8 dígitos. Aliceweb2, 2012. Disponível em:<http://aliceweb2. mdic.gov.br//consulta-ncm/index/type/importacaoNcm>. Acesso em: 15 fev. 2014.

FERNANDES, Rosangela Aparecida Soares; BRAGA, Marcelo José; LIMA, João Eustáquio de. Elasticidade na transmissão de formação espacial de preços de leite ao produtor nos principais estados brasileiros. In Congresso Brasileiro de Economia e Sociologia Rural, SOBER. Universidade Federal de Viçosa. Minas Gerais, 2008.

INSTRUÇÃO normativa n. 62: uma decisão consciente para o setor lácteo. Análise e Indicadores do Agronegócio. Instituto de Economia Agrícola - IEA. São Paulo - SP, v. 7, n. 2, fev. 2012.

MACHADO, Paulo F.; CASSOLI, Laerte Dgher; CARDOSO, Felipe. Qualidade do leite: o que 2007 mostrou para a cadeia do leite? Boletim do Leite CEPEA. São Paulo, ano 14, n. 162, p. 6, jan. 2008.

PONCHIO, Leandro Augusto. Um balanço de 2003. Boletim do Leite CEPEA. São Paulo, ano 11, n. 118, p. 3, jan. 2004. 